\title{
4 \\ Visual Noise in the New Photography
}

\section{THE UNCLEAR}

Once photography achieved the level of precision and accuracy that painting and illustration had sought for centuries to accomplish, a breed of talented artists needed to find a new tune. Impressionism, expressionism, and related forms of twentieth-century image making henceforth emerged. Now that photography and filmmaking have matured, their capacity to capture and display realistic representations of the world has become banal. This chapter explores one of the most recent outcomes of this legacy: photography's turn from realism to visual noise in the digital age. To connect visual noise to the broader media ecology of twentyfirst-century communications, the chapter focuses on German photographer Thomas Ruff's experiments with noise and digital distortion in the late twentieth and early twenty-first centuries. Three core tenets of visual noise are identified in Ruff's work, all derivative of a larger media aesthetic rooted in technological failure. The first is a renunciation of classical norms of visual representational and pictorial convention. Photography is an especially intriguing platform for exploring this because it has been implicitly associated with visual truth, realism, and authenticating documentary capacities for over a century. I argue that the development of the New Photography genre in the 1970s foreshadows styles of visual ambiguity operative in twenty-first-century glitch art and that Ruff's aesthetic trajectory, from his early training to his more advanced work, mirrors wider shifts in the development of contemporary aesthetics.

The second tenet of visual noise in Ruff's work analyzes the obfuscation of clear meanings by building on correlations between color as noise established in chapter 3. Here, a noisy, anti-communicative aesthetic correlates with Judith 
Butler's notion of "incompossibility," referred to in the Introduction. The deliberate failure to provide hermeneutic closure has a long tradition in twentieth-century theory and practice. In digital art, hermeneutic breakdowns tend to manifest as an inconsistency between an image's appearance on screen and its source code, examined here in Ruff's work, though equally operative in chapter 5 and in Jodi's work, discussed in chapter 2.

The third tenet, discussed only briefly, concerns cultural and psychological projections of failure onto machine technology, coupled with a consideration of our motivations for doing so. Examples include a website stalling, failing to load, or a cell phone spontaneously shutting off or dropping a signal. From the machine's perspective, it is operating in precisely the way it was programmed to respond to this situation. There is no failure. Disparity arises through the cultural expectations for efficiency and undisturbed visual content that we unconsciously project onto it.

The chapter begins with an overview of Ruff's early work and training, followed by a definition of the New Photography. Section III addresses Ruff's nudes (1999-2012), drawing on Greg Hainge's discussion on the topic. Section IV turns to visual noise in Ruff's jpegs (2002-), which includes a technical exegesis into JPEG compression. My conclusion points to the persistence of visual glitch styles in popular culture, construed as budding artifacts of unfulfilled desires in a world of high-tech. As in chapter 3's analysis of Ryan Trecartin's work, my focus here lies less with identity politics, pornography, or catastrophe journalism (though I touch on all of these) and more with communicative breakdown, and the ways in which it resonates with the aesthetics of visual noise in twenty-first-century media culture.

\section{THOMAS RUFF AND THE BECHER SCHOOL}

Thomas Ruff was born in Germany's Black Forest region, in Zell am Harmersbach, in 1958. In 1977, he attended art school at the Staatlichen Kunstakademie Düsseldorf, where he later became a professor from 2000 until 2006. He found early success as an international art photographer, exhibiting his work at such esteemed venues as Documenta 9 and the Venice Biennale (in 1995 and 2005). He is represented by the Gagosian Gallery and David Zwirner in New York, and his work is now included in the permanent collections of the Metropolitan Museum of Art, the Hamburger Bahnhof Museum for Contemporary Art, Berlin, and the Art Institute of Chicago.

As a student, Ruff attended classes with other nascent international art stars, including Thomas Struth, Candida Höfer, Axel Hütte, and Andreas Gursky. Together, they benefited from the teachings of the well-known artist couple Bernd and Hilla Becher, esteemed for their serial photographs of industrial-era objects (like refineries and factories) in a flat documentary style. ${ }^{1}$ The Bechers had a lasting influence on their students, many of whom continue to reproduce their matter-of-fact, distanced style, developing it into what has now become known as the "Düsseldorf School" (or sometimes the "Becher School") of contemporary 
photography, typified by a direct, seemingly uninvolved and aloof "objective approach" to image making. The stylistic approach can be contrasted with the "freer pictorial language" one finds in highly emotional commercial or journalistic practices. ${ }^{2}$ Even many art students who did not study with the Bechers associate themselves with the Becher School and its method, and at times, German photography is on the whole incorrectly conflated with it. ${ }^{3}$

In line with the Becher School's approach and progeny, Ruff's early photographs are cool, detached, and aloof. They consistently deny symbolization, thwart narrative structure, and avoid personalization. One of his very early series, Interior (1979), for instance, consists of a set of frontal color images of the dwellings of friends and family from his native Black Forest region. At first glance, the images seem flat and boring, perhaps because no event or action is occurring. They read as banal documents of one's personal space, with no theme or subject beyond this. Unsurprisingly, when Ruff first showed the Interior images to his mother, a homemaker who grew up on a farm, and his father, a technical director at a ceramics factory, they said, "Perfect. That's exactly how it looks in our house." them as just this: flat, straightforward documents of interior spaces. They did not see the images as "art," but rather as precise, faithful reproductions of reality. "I think my parents didn't realize that I went to [school to] study art," Ruff explains. "They thought, Thomas is going to study photography," a good profession with direct, unpretentious, practical sensibilities. Their reaction to the photographs points to the subtlety of the Becher School's preference for "flat and dry anonym-

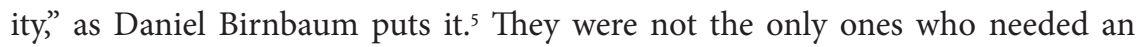
explanation for how and why its aesthetic looked the way it did.

The crux of the Becher School's aesthetic can be identified by the way it goes almost unnoticed as "art." 6 Another illustrative example from Ruff's early work are the now well-known Portraits (1981-87), a series consisting of several large-scale color photographs of friends and colleagues at the Art Academy. Each person featured in one of the images was photographed alone, head-on, without expression or emotion. The same framing technique is used throughout the series, emulating the often-rigid guidelines for passport photographs. The flat and banal approach again mimics the "objective," quasi-scientific style of technical photography, while also foreshadowing a machine-like detachment that develops in Ruff's later work. ${ }^{8}$ The Portraits were shown at galleries in Germany while Ruff was still a student, followed by exhibitions at important institutions in Europe and elsewhere. ${ }^{9}$ And yet, despite the early success of this work, the artist remains dissatisfied with them and is irritated by particular viewers' interpretation of his Portraits..$^{10}$ It is not the specific meaning that people project on them that disappoints him, but rather, the imposition of any meaning at all. To amend the situation, in 1986, he enlarged the format from $18 \times 24 \mathrm{~cm}$ to $165 \times 210 \mathrm{~cm}$ and replaced the individually selected background colors with evenly lit, monochrome gray ones. Although the changes were minor, they effectively removed the possibility of linking the images to any 
expressive meaning or poetic content. The new series refocused viewers' attention on the frontal poses only, intensifying the anonymity, inexpressiveness, and serial nature of the "larger-than-life faces," as Ingrid Hoelzl and Remi Marie out it. ${ }^{11}$ For Birnbaum, it is this absence of personal affect and involvement that effectively marks the artist's "objective" style, coinciding with the School's aesthetic. ${ }^{12}$ I return to Ruff and his noisy digital transformations after further contextualizing the German School alongside the equally detached aesthetic of the mostly American New Photography genre in the next section.

\section{The New Photography}

The denial of meaning, hermeneutic closure, and comprehensive communicative transactions are tried and true marks of experimental art and photography from Duchamp and Warhol through John Baldessari and Jeff Wall (as they also are of media archaeology and postwar aesthetics, as discussed in the Introduction and chapter 2, respectively). What distinguishes the Becher School and Ruff's work in relation to the history of photography is their unique role catalyzing the development of the "New Photography" movement and its embrace of pseudo-objective scientific methods.

For French art critic Jean-François Chevrier, the New Photography emerged in the 1970 at the moment when the "photograph" in the traditional sense became a tableau (painting or picture), as Michael Fried notes. ${ }^{13}$ In the context of media archaeology, the New Photography performs a deadness in the image, meaning a mood that emulates a death-like vacuity. For example, the new approach required artists to adopt an attitude of neutralization and quasi-scientific stance to their subject matter, in contrast to the highly emotive poet/artist pathos otherwise key to the history of painting and much of modern art. William Jenkins, curator of the defining 1975 exhibition New Topographics: Photographs of a Man-Altered Landscape, held at the International Museum of Photography at the George Eastman House in Rochester, explains the "viewpoint is ... anthropological rather than critical, scientific rather than artistic." ${ }^{14}$ His observation is insightful in more ways than one. Telltale signs of the genre include the now vernacular large-scale color print and photographs produced for a gallery or museum, rather than a magazine or newspaper. Robert Adams, Lewis Baltz, Joe Deal, Frank Gohlke, Nicholas Nixon, John Schott, Stephen Shore, Henry Wessel Jr., and the pioneering Bechers were among the artists featured in the exhibition. Once arriving in front of one of these massive prints, Fried observes, the viewer is confronted with a new kind of aesthetic experience. These images do not draw on straightforward methods, he explains, nor do they aim to communicate direct experiences (and herein lies the irony of Ruff's parents' "straight" response to his work). If the images seek to communicate anything, it is a rhetoric of anti-communication, intended to undermine century-long assumptions linking photography to notions of transparency, authenticity, and visual realism. Moreover, because the New Photographic artists 
primarily depicted the post-Nature landscapes of suburban and urban America, their work could not help but invoke an archaeological deadness in both style and content.

What then appeared to be the largely unannounced goals of the New Photography genre-like those of the Becher School-incited visual and historical ambiguity, without appearing to do so-at least not explicitly. By producing moments of apparent "openness and contradiction," as Chevrier puts it, the genre eschewed modernism's reactionary impulses for grand narratives of social, political, and technological progress. ${ }^{15}$ In the same way that the cultural context of the late 1960 s and 1970 s brought about increasing forms of political disillusionment and sociocultural disappointments, he suggests, this new breed of seemingly deadpan photographers sought to dismantle outdated responses to expressionism and delusions of grandeur. In creating an awkward distance between the image (object) and an individual's (subjective) aesthetic experience of it, as Chevrier suggests, both the New Photographers and the Becher-led German School echoed broader forms of cultural alienation and sociopolitical segregation between a subject and the world they lived in.

Early on, Ruff played a central role in the formation of the Becher School's aesthetic and in turn, was equally influenced by the New Topographic artists. In his later work, however, he has moved in a new direction, away from the pseudo-objective, and towards experimental techniques that lend themselves more directly to digital glitch, noise, and blur. In the 1990s, Ruff began investigations into various techniques utilized in the reproduction of digital images, from the stereoscope in his Stereo-photos (1994), to the telescope in Stars (1989-1992), and the Minolta Montage Unit (an image-generating machine for the creation of composite faces used by police departments in the 1970s) in Portraits (1994 and 1995). His more recent engagement with digital practices range from composite picture making to the use of night-vision technologies, hand tinting, digital retouching, photomontage, and appropriated imagery from such dissimilar sources as scientific archives, newspapers and more recently, the internet. He has also since addressed disparate genres and imaging conventions in the history of photography from collage techniques in Newspaper Photographs (1990-91) and Retouched (1995), to scientific imaging in Stars and Machines (2003). ${ }^{16}$ In sum, true to his training, Ruff's style remains rooted in exceedingly controlled methods to ensure a lack of interpretive depth. His more recent work remains void of personal psychology though it bids adieu to the quasi-scientific objectivity that both the Becher School and the New Topographic artists implicitly sought.

\section{RUFF'S NUDES}

In the 1990s, Ruff stopped using a camera altogether. He produced instead a new series of works barely resembling the documentary style of his earlier training. ${ }^{17}$ 
This work drew on prêt-à-porter methods of appropriation, namely, foraging and mining the internet for pre-existent images. The nudes series is a prime example. He began the series in 1999, five years after the launch of Netscape in 1994, during a time when internet cultures were beginning to bubble. A friend of his suggested it might be interesting for him to turn to the subject of the nude but, after facing his lack of interest in traditional approaches (such as working with live models), he began researching the subject of the nude on the internet. ${ }^{18}$ The first set of examples he encountered were the classics, nudes taken by well-known fashion photographers like Helmut Newton and Peter Lindbergh, carefully composed photographs that were not especially inspiring to him.

Ruff next decided to try expanding his search terms. The results produced an astounding mass of internet pornography. "There were so many [pornographic] images," Ruff explains, images that were "much more honest than all the artistic nude photography . . . I had seen previously." ${ }^{19}$ For early internet media, pornography was (and still is) prosaic, inviting divergent critiques beyond the scope of this discussion. ${ }^{20}$ To skirt the issue entirely, however, would be negligent. At the very least, it can be agreed that pornography is candid, showing a lot and holding back very little. In contrast, the erotic image can be said to play more subtle games with visual mystique, perception, and hiding and revealing. In photography, the distinction between "the naked and the nude" is often used to distinguish between porn and erotic art. Some will likely disagree with this quick delineation and, of course, the harder we press them, the more quickly any distinction between pornography and erotic art, or the naked and the nude, will fall apart. Nonetheless, a loose contour is drawn here to show how Ruff moves between them, further challenging their constructed distinctness.

Ruff was drawn to the pornographic images he found online, not for their sexual nature, he explains, but because of their "low-resolution pixel structure." ${ }^{21} \mathrm{He}$ found that the unintentionally noisy aura cast across the majority of them resembled the abstract compositions he had been toying with on his computer. The key difference was that the noisy appearance of internet porn was due to its low resolution and excessive copying, whereas the abstract compositions the artist had been experimenting with were deliberate abstractions. Nonetheless, the visual parallel guided his decision to move forward with the topic and create a series of related images, which eventually became nudes.

Using the techniques he had already been experimenting with at home (software-based distortion effects, modified color, and the removal of intrusive details), he transformed his downloaded selections to the point where the pixel structure and representational content were highly ambiguous. ${ }^{22}$ In other words, he enlarged the "found" internet images as much as he could, without completely eclipsing the capacity to loosely recognize the content from afar. By maximizing the size of an already extremely low-resolution internet image ("blocks of eightby-eight pixels") it was inevitable that any additional noise or digital distortion 
would further obfuscate their readability. This was especially the case "at close range," where all of the images became "unreadable representationally," akin to the dots in a pointillist painting. ${ }^{23}$ This was precisely the effect Ruff sought, one he had previously attempted to emulate through more contrived means. It also marked an important break with the medium's conventional use and the straightforward realisms of the Becher School, which now seem to fit more squarely in traditional histories of the medium.

Ruff produced his final results by smoothing over the rawness of the stark source material, producing a whimsical, blurry-pixel eroticism; a Gerhard Richter for the internet age. Abstraction softened and accentuated the images' visceral and graphic qualities, shifting their collective identity from "bad Internet porn," to deliberately staged imagery that appeared to look like "bad art." ${ }^{24}$ Greg Hainge offers a detailed argument of Ruff's images, discussing the various techniques the artist uses, including cropping and reframing an image so that bodies and limbs bisect the entire space, sometimes vertically, as in nudes ga o8, and sometimes diagonally, as in nude reeo7 (2001), nudes ez14 (1999), and nudes dgo6 (2003). ${ }^{25}$ In the latter, one leg creates the base of the diagonal bisection, framed by an overlapping folded leg, creating an arrow towards the top left-hand corner of the composition. ${ }^{26}$ The lines are further accentuated with the white shoes, deepened again by the back seams on the subject's translucent stockings. In other images, Hainge notes, body parts are used to horizontally frame the image, such as nudes noe o9 (2000) and nude gu o6 (2000), where an inserted dildo is seen at the very center of the image, tracing a line out to the left of the frame with a stroke of brilliant red and translucent blue. This same kind of dissection reoccurs in nudes ez 14 (1999), where a "dark space between the profiles of two women about to kiss" creates a fuzzy visual tension by activating the negative space. ${ }^{27}$

As noted, the nude series also utilized visual techniques in blur and ambiguity to play with historical tensions between the naked and the nude. Where the former suggests a cruder, raw depiction of a naked body (i.e., porn) the latter slides (or attempts to slide) into the domain of "the erotic," often affiliated with art. In other words, if the naked is akin to the straightforward style of the pseudo-objective Becher School, then the nude (and by extension the erotic) denotes a somewhat nuanced and more seductive mode of simultaneously revealing and concealing in an image. Is this a tenet of glitch aesthetics? Possibly. In traditional pornography (and photography), being out of focus, focusing on the wrong object, or missing the "money shot" definitively indicates failure in a work or series of images. This is illustrated in John Baldessari's black-and-white photograph Wrong (1966-68), discussed in the Introduction. Here, however, this genre-defining convention is rewired into a new circuit that curtails a clear signal to produce instead ambiguous visual noise. Put differently, the failure to show too much becomes an entry point for a poetic language of ambiguity; a seeming accidental transformation of signal into noise. It is also at this point that Ruff's work gestures towards the 


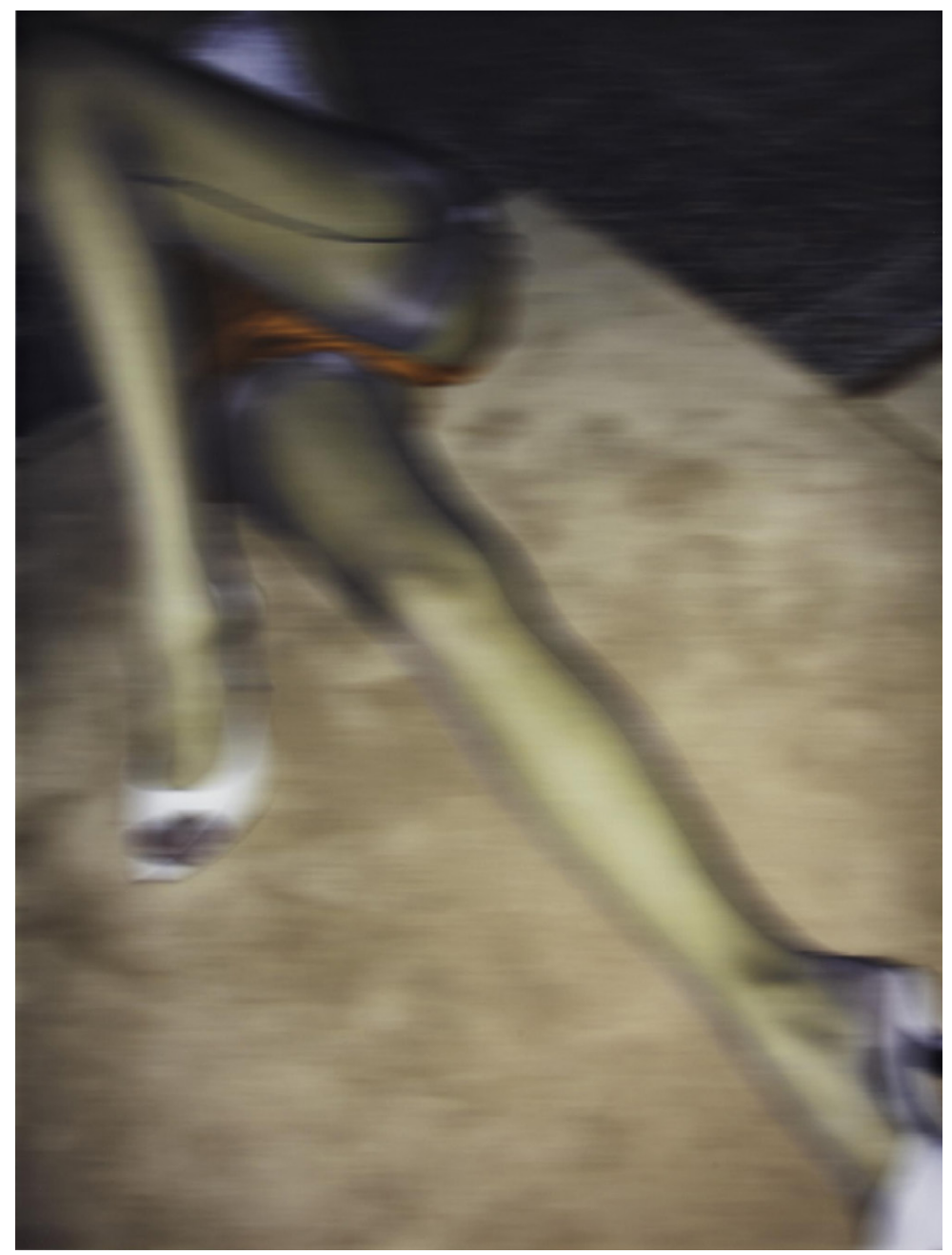

FIGURE 17. Thomas Ruff, nudes dgo6 (2003). Visual noise fuses barely stockinged legs with a beige carpet in the background. () Thomas Ruff / SOCAN (2019).

first and second tenets of failure noted above: the use of noise to deny cultural norms for clear visual communication, coupled with a deliberate introduction of uncertainty in the development of a visual rhetoric of anti-communication. This further underscores how nudity itself operates in the series as an allegory for the ambiguous haze of perception, as such. Unlike his predecessors, Ruff's new work begins to draw on twenty-first-century techniques that rely on optical ambiguity to reflect new cultural concerns with obfuscation, transmission, and comprehension. ${ }^{28}$ 


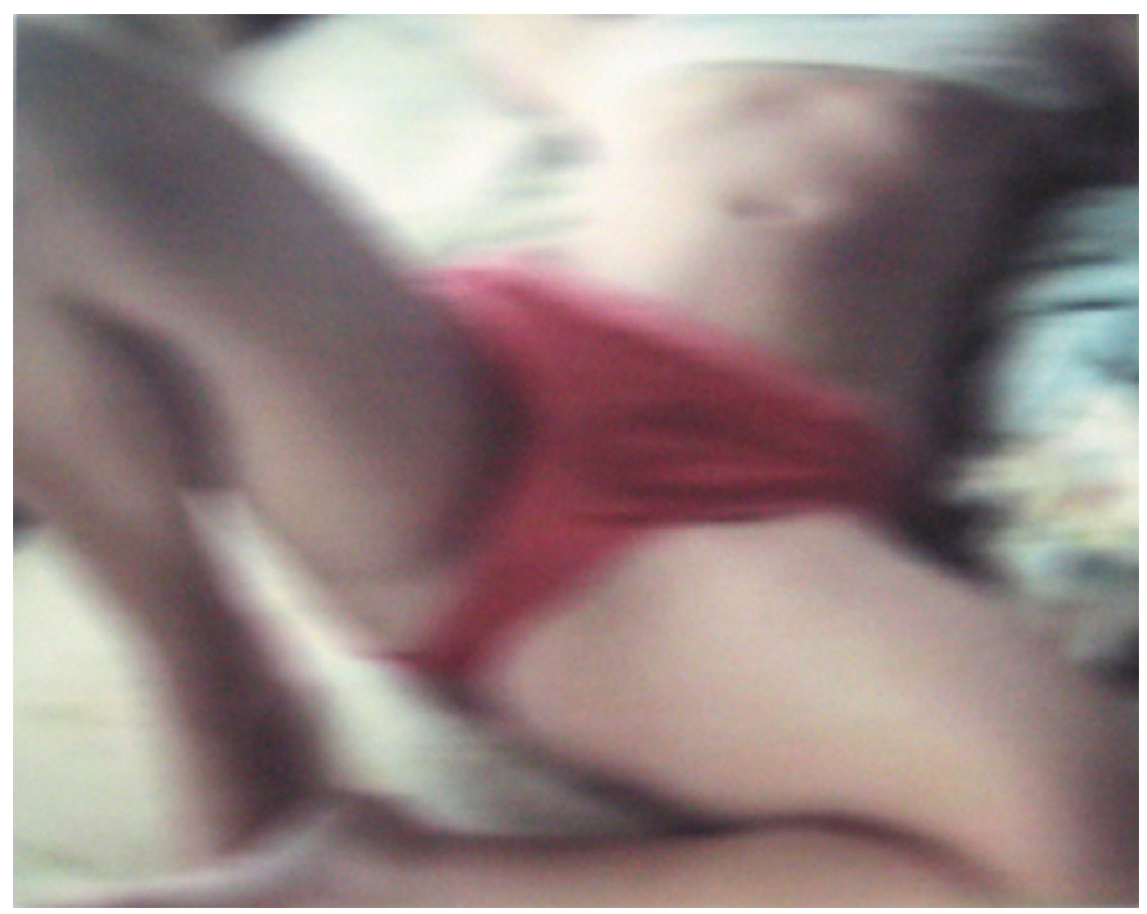

FIGURE 18. Thomas Ruff, nudes reeo7 (2001). Photo noise softens the candidness of a classic "money shot" pose. (C) Thomas Ruff / SOCAN (2019).

We can also identify in the nudes an explicit attempt to undermine classical traditions of representation and, Hainge notes, unified theories of perception, such as those presented in the markedly German tradition of Gestalt. ${ }^{29}$ Defined as a psychological and holistic approach to artistic creation, in Gestalt all aspects of a work play a necessary and vital role in the formation of the whole. Many Gestalt tendencies derive from the work of Bauhaus artist Wassily Kandinsky ${ }^{30}$ and extend through colorists Josef Albers and Johannes Itten, Russian formalism, Mondrian, the architecture of Le Corbusier and Bruno Taut, and the interior design of De Stijl and the Eames. On the whole, Gestalt is linked to modernist tendencies and telltale signs of Ruff's effort to work against this tradition, Hainge argues, includes the use of cropping to cut off certain body parts, especially head and eyes, offcenter compositions, and produce deliberately "off" color combinations (like neon green and white). ${ }^{31}$ In this way, some of the nudes qualify for the "accidental color aesthetic" discussed in chapter 3. Finally, the open structure of each image, with hands, heads, and limbs cut off, allows us to see how the motif of consistently severed body parts echoes the postmodern sentiment of the moment, with its insistence on the fragmentation of perception and modern life, always already 


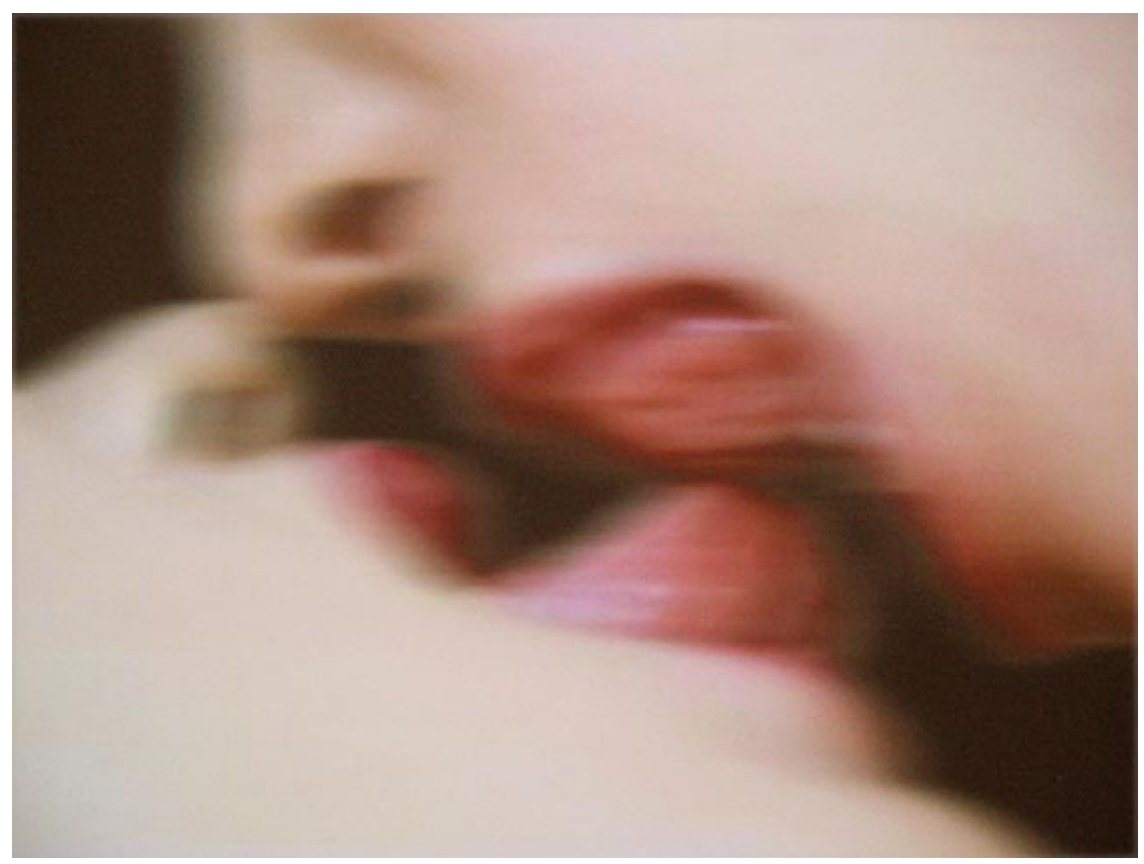

FIGURE 19. Thomas Ruff, nudes ez14 (1999). The two sets of blurry, painted lips create a tension in their mirror-image. (C) Thomas Ruff / SOCAN (2019).

mediated by new media technologies. Noisy color becomes the primary means to most accurately reflect this paradigm.

Michael Fried goes so far as to suggest that Ruff's color treatment has an affinity with fauvism and German expressionism, given that both movements concerned themselves with "garish color," as he puts it..$^{32}$ However, both fauvism and German expressionism use bold and saturated colors, while Ruff's colors are always at least a bit muted and unsaturated. This occurs in part because of the technological limitations in forcing such extreme enlargements of low-resolution digital images, but also as a result of his artistic choice. Ruff's colors are loud, but they do not overtake the image, as one could argue of fauvism. In fact, if Fried were to seek a more appropriate digital correlative for the bold colors of fauvism or German expressionism, he might turn to the racy colors of datamoshing, discussed in the next chapter.

Regardless of the relative weight of color in the nude series, the work as a whole exhibits a proclivity for blur and noise as its primary motif and mode of expression; noise as surface phenomenon is conflated with the signified content of the images. Visually unclear shapes and objects speak a language of uncertainty that is in fact more accurate and "honest"- to borrow from Ruff's description of internet 


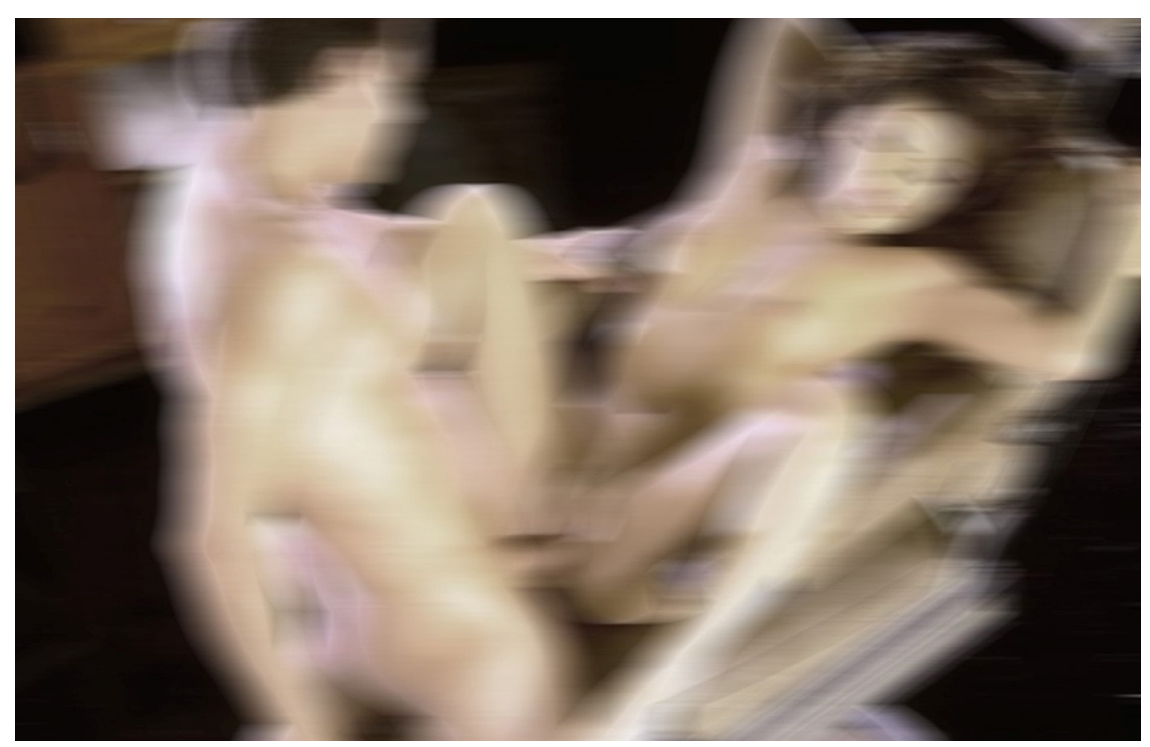

FIGURE 20. Thomas Ruff, nudes emo8 (2001). Bodies are blurred and repeated to suggest an abstract elegance in mechanical movement. () Thomas Ruff / SOCAN (2019).

pornography - than the perpetually deferred promise of clarity, the fulfillment of desire, or any other such industry-derived rhetoric around "crisp and clear" digital colors. Ruff's colors are candid about their falsity, they do not attempt to communicate anything beyond themselves, and this, in turn, makes them "honest." This is also why Ruff's use of color is void of nostalgia. As I argue in chapter 3 , coloras-color or, color-as noise always carries a balance between signified imagery and its material form of appearance. Similarly, in an interview with Paul Pfeiffer, Ruff explains his goal to "reflect the medium in the image itself" (i.e., Wollen's foregrounding), one must "always be aware of the medium while using it." ${ }^{33}$ Chromatic noise, again, becomes the primary technique to accomplish this, not because the color is bold or outlandish, but because color and shifts between light and dark are the only vehicle through which pixels can collectively resolve themselves as data on screen, whether as clear, communicative signal or fuzzy and ambiguous noise. ${ }^{34}$ Here, the first tenet of Ruff's work-the failure to instantiate norms of visual communication - takes on the cool, slightly distanced approach from the Becher School and New Topographics, and in so doing, segues into the second and third tenets: the intentional blockage of meanings and failure to provide a comprehensive communicative exchange, often by way of technological mediation. The next and penultimate section of this chapter further considers the third tenet, where visual noise operates through the graphic attributes of the JPEG image while also speaking to a set of low-level human fears projected onto them. 


\section{RUFF'S JPEGS (2000-)}

We now turn to Ruff's noisiest series: the jpegs (2002-). Like the nudes, the jpegs do not gesture towards nostalgia in the slightest. Rather, in typical Ruff-style, they adopt a cool disposition akin to the detached eye of a scientist observing phenomena under a microscope, which, I argue, also becomes a blank slate for the projection of cultural fears. ${ }^{35}$ The jpegs began in 2002 as a series exploring crisis, failure, and breakdown, using the (perceived) "failure" of JPEG compression codecs to do so. To create this work, Ruff focused on scenes of disaster, usually global in consequence, from the crumbling of the twin towers in New York to the U.S. bombing of Baghdad; the Iraqi Army burning oil fields during the second Gulf War; satellite photos attempting to prove the existence of weapons of mass destruction in Iraq; the Russians in Georgia and Grozny; and the Khmer Rouge's killing of civilians in Cambodia. ${ }^{36} \mathrm{He}$ gathered low-resolution images from the internet and exacerbated their grainy, lowres appearance by downsampling them to about $100 \mathrm{~kb}$ per image. He then enlarged them again to a monumental size ranging from $188 \times 188 \mathrm{~cm}$ to $297 \times 364 \mathrm{~cm}$. The result was a uniform series of dramatically pixilated and blurry images of barely recognizable scenes of disaster, rendered at a whopping $1.3 \mathrm{~GB}$ per image file. As with the nudes, by significantly increasing the compression artifacts in the already lowresolution images, he accentuated the pixel structure to intensify visual noise, highlight blocks of color, and obscure objects and elements depicted therein. In the artist's words: "I had to re-scale the files to a very small size and then compress them as the worst possible quality JPEGs." ${ }^{37}$ The technique appears to be the same as the one used in nudes but, according to the artist, in the nude series, he used blurring because the "material was so ugly,"38 while in jpegs, pixilation techniques were used to investigate the material logic of the compression scheme itself, to which we now turn.

\section{JPEG History}

In 1987, the Joint Photographic Experts Group (JPEG) produced the first single standard of image data compression for web users. Between 1986 and 1994, the committee created the first international standard for still (single-frame) image compression, intended to ensure global compatibility. The "Joint" in JPEG refers to the link between the International Standardization Organization (ISO), which develops standards in a wide range of fields, from freight container dimensions to ISBN numbers for books, and its specialized partner organizations, the International Electrotechnical Commission (IEC) and the International Telecommunication Union (ITU). ${ }^{39}$ The publication of the JPEG codec as a joint ISO/IEC standard in 1994 coincided with the launch of the first commercial web graphic browser, Netscape Navigator, a merger foreshadowing the centrality of digital images in today's media culture.

At the same time, and as scholars have recently noted, algorithmic compression is in no way unique to digital media or the internet. To note only one example, 


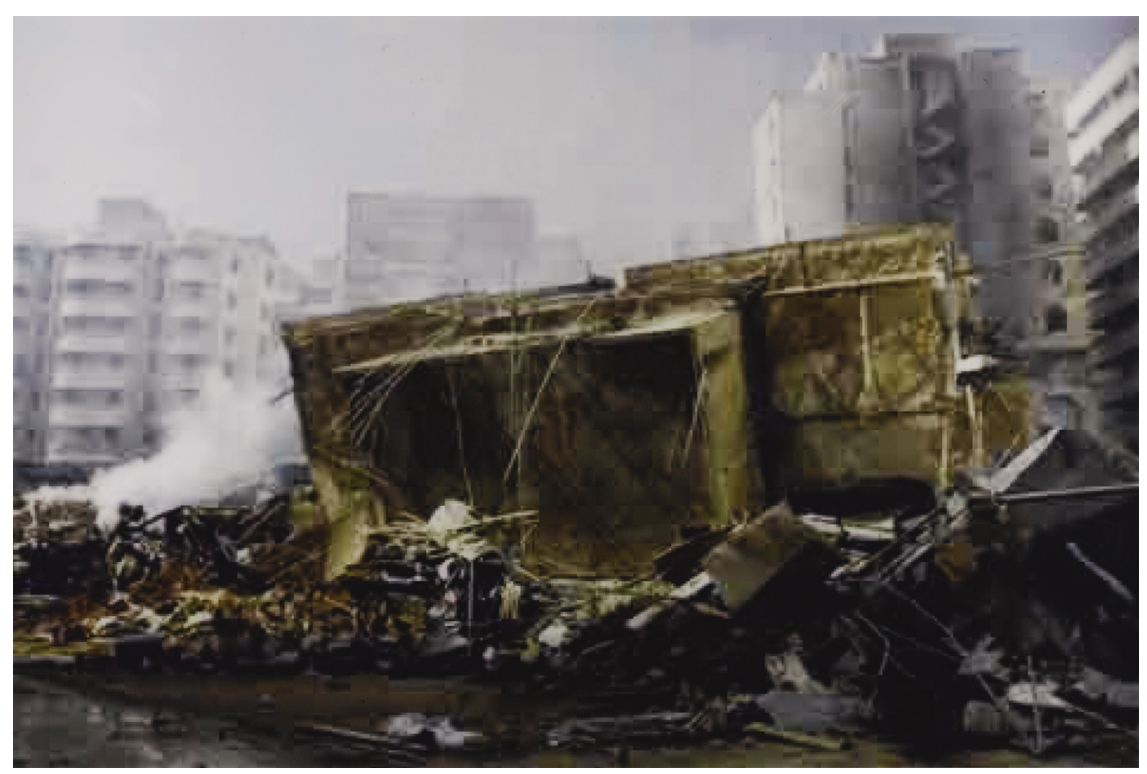

FIGURE 21. Thomas Ruff, jpeg wlo1 (2006). Tight cropping leaves a viewer uncertain as to where or when this destructive event occurred. The compressed title barely gives a clue. (C) Thomas Ruff / SOCAN (2019).

recall Filippo Brunelleschi's fifteenth-century demonstration of linear perspective which necessarily involved the compression of three-dimensional space onto a two-dimensional plane, as also noted in the Introduction. Decompression occurs when any viewer uses the synthetic processes of perception to decode visual information. ${ }^{40}$ To press this a step further, we might also draw on Alexander R. Galloway's recent proposition that the history of media is a history of compression. For Galloway, and I would agree, we are undergoing a progressive "cataclysmic compression of modern life." This applies to multiple aspects of culture, from visual art to philosophy and economic theory. He gives a range of illustrative examples from the compression of thought in philosophy, to the notion of "the roundoff" in engineering, denoting the process of digitizing data so that the nuances of analog information are "rounded off" to the closest digital integer. Galloway also notes the treatment of redundancy and ornament in minimalism, where the gradual deletion of surreptitious material becomes a definitive motif of the entire genre. ${ }^{41}$

Both Philip Agre and Bernard Stiegler have proposed similar theories, largely complementary to Galloway's. The notion of "grammatization," which Stiegler borrows from Derrida, denotes how human experience and activity are compressed into units or "grammars of action." 42 Similarly, Galloway notes, recent scholarship by Luciana Parisi on the "incompressible" and by Hito Steyerl on the "poor image" 
do much the same work. One could also include recent studies of increasing repetition in pop music, inadvertently leading to an overall compression in the genre. ${ }^{43}$ In one sense then, Galloway's theory of compression is compatible with dominant tendencies already known and accepted in the media environment. His focus on the gradual reduction of information, rather than industry-driven discourses of constant improvement also falls in line with the aims of media archaeology.

To return to the JPEG, it is a compression algorithm known as a codec. A codec regulates how information is compressed and decompressed within digital technologies (see chapter 1). ${ }^{44}$ The particularity of the JPEG codec derives from its capacity to compress continuous color images of "real-world" subjects, as found in conventional photography and paintings. Color is the name of the game in JPEG compression. The format's defining attributes are its capacity to translate massive amounts of nuanced color information into a much smaller and manageable series of abstract digits. The key to understanding JPEG compression is that with it, a "photograph," in the traditional sense of the term, ceases to be a photograph because a JPEG "image" is in fact entirely made up of a series of numerical abstractions and computer algorithms. A JPEG is therefore no longer tied to a specific light-capturing medium, but instead a linear and numerical organization of color information that can be reduced to binary data.

JPEGs also employ a "lossy" method of data compression. This means its compression logic enforces the removal of "redundant" information, based on the sensitivity of a so-called standard human observer. Lossy compression is one of two standard methods for digital image compression. It is the most common, typically found with the majority of downloadable sound and image media. Lossy compression also involves a good deal of information loss, the space for and through which noise emerges. The $\mathrm{MP}_{3}$ format for instance uses psychoacoustic filtering to remove data deemed unnecessary to reproduce a normatively acceptable sound quality (again, defined by a so-called standard observer) with the goal of making the file smaller. At the same time, when $\mathrm{MP}_{3}$ files circulate online, they do so through "lossless" networks which is to say, the loss of data typically occurs when the file is originally created, not by way of network distribution.

The second core compression method is "lossless" compression, which, as its name suggests, involves negligible data loss. Because the accurate transmission and reception of data is fundamental to all networking, whether wire, radio, internet, or telephone, the majority of data compression is lossless, where zero data loss is routine. ZIP and DMG files are two examples of lossless compression. In both cases, all data are kept on file but there is a removal of redundant data upon encoding that is later restored upon decoding or, the decompression of the file at its end point (i.e., when you click on a zip file to open it). ${ }^{45}$ Where lossy images are useful for saving time and space and for increasing processing speed or facilitating transmission and circulation on the internet, lossless images are more useful for high-end print reproduction where detail is required. Because the JPEG's lossy 
compression sequence is bare bones, it is much easier to tweak and degrade its rendering algorithms to produce visual "noise."

There are also different levels for rendering the quality of JPEGs. Photoshop, for instance, offers a range from one to twelve, with twelve being the least amount of compression for the file, retaining the most amount of information and producing a JPEG with the highest possible image quality. In contrast, a JPEG quality of " 1 " offers a version of the image that will be compressed into the smallest file size and is the most efficient choice for internet uploading, downloading, and circulation, but will also inevitably result in artifacts and pixilation. As noted, it was this most extreme form of JPEG compression that Ruff chose for the images in this series, successfully highlighting the most dramatic discontinuities between adjacent pixel blocks. ${ }^{46}$

In sum, the reductive logic of compression, outlined here, is central to Ruff's jpegs series. There is the exploitation of the codec and pixelated rendering already described. There is also a use of compression language to nominalize each image in the series. Many images are given titles that appear as codes: "cao2," "wlo1," "kao1," "lao1," "do1," and so on, themselves so compressed they are not even words anymore (like Shannon's definition of "Information" noted in chapter 1). The titles thus create additional conceptual noise that further complicates meaning and a viewer's ability to decode when or where the image is sourced from, let alone when it was taken. ${ }^{47}$ This same logic of compression also extends to the artist's treatment of otherwise devastating international tragedies. This is not to be taken as a coldness, in the sense of a lack of concern or care for the well-being or tragedy of others, but rather, as a critical and mimetic performance of the impersonal nature under which the vast majority of us are increasingly exposed to images of war and international disaster. Many of us increasingly access the world through low-resolution newsfeeds and cell phone screens where what happened to whom and when is often unclear, save for the fact that something catastrophic occurred (again).

\section{BEAUTY IN A BROKEN WORLD}

Despite Ruff's cool style, appropriation of error, and detached mode of display, there is still some old-world beauty to be gleaned from his digitally distorted work. All of the images discussed in this chapter are still images, which is to say that they are frozen and static in time. By definition, they open a space for a pause and reflection. In this pause, Ruff's visual noise-for all its explicitness and exploitationstill manages to generate a peaceful moment of contemplation in our otherwise nonstop flow of information. In this space, beauty returns as the unresolved truth of seeing and being seen. Put differently, what is beautiful in these images is their strategic break with illusions of transparency so deeply entrenched in the history and rhetoric of Western culture and photography in particular. Photographic conventions have for decades laid claim to a crystal-clear, objective reality. In some 
ways, this is precisely what Ruff's early work sought to do but never seemed to drive home on a mass scale. This is undoubtedly not the case with his later work where noise is clearly unclear. His denial of objectivity and (illusions of) visual transparency render the invisible noise of our media environment on the very surface of the image, however frustrating their cognitive reception may be. In this way, his artificial noise is perhaps one of the most accurate reflections of how daily life is actually experienced in a media-saturated society: unclear, dismal, and exceedingly reductive.

At the same time, this is not to say that Ruff's work is overtly political, or even tacitly so. Rather, in allegorizing the conditions of visual and communicative failure, he subtly iterates what is already troubling in modern life and experience. Jodi Dean's concept of "communicative capitalism," introduced in chapter 3 , is again useful for describing this condition as one marked by "noise" and a ubiquity of failed communications. Communication fails in global capital because it no longer functions in the sense of a "communicative bridge," as noted by John Durham Peters (chapter 1). That is, capitalism no longer communicates at all, but instead excels at broadcasting noise, while laying claim to the inverse. "What hinders communication" today, Dean explains, is "communicability itself." ${ }^{8}$ Circa 1990, Luc Boltanski and Eve Chiapello identified a similar tendency in contemporary art, a failure running alongside the neutralization of critique. Their claims, albeit referring the post-1989 political situation, connect politics and art, wherein both have lost the possibility of generating meaning, returning us to the same contradiction between content and mode of expression. ${ }^{49}$ Ruff's work shows us how the internet is a paradigmatic example of this gap and failure across art, politics, and cultural communications writ large. He does so elegantly and "honestly," which is to say, he makes poetry out of the sad fact that the more data we produce, the less meaning we find. He is also hardly alone in using glitch techniques to do so, as we have seen in the previous two chapters and will see again in the chapters that follow. 